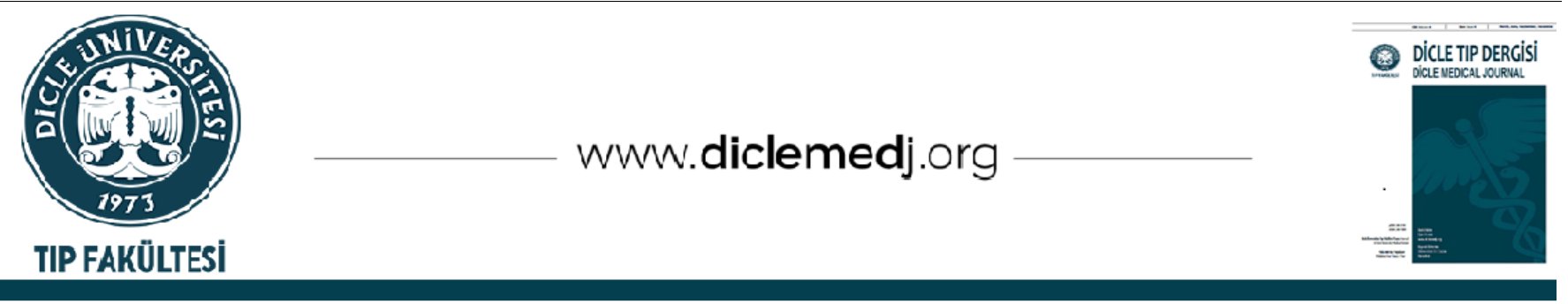

Özgün Araştırma / Original Article

\title{
Tip 2 Diyabetes Mellitusta Retinopatinin Gözün Ön Segment Parametrelerine Etkisi
}

\author{
İrfan Durukan ${ }^{1}{ }_{1}$ \\ 1 Era Göz Hastanesi, Göz Kliniği, Ankara, Türkiye \\ Geliş: 13.05.2020; Revizyon: 24.11.2020; Kabul Tarihi: 24.11.2020
}

$\ddot{0} \mathbf{z}$

Amaç: Aksiyel uzunluğu ve ön segment yapılarını farklı retinopati evrelerindeki Tip 2 diyabetes mellituslu (DM) olgularda karşılaştırmak.

Yöntemler: Çalışmaya dahil edilen Tip 2 DM'li hastalar diyabetik retinopati (DR) durumuna göre üç gruba ayrıldı: retinopatisi olmayan hastalar (non-DR grubu), non-proliferatif diyabetik retinopatili hastalar (NPDR grubu) ve proliferatif diyabetik retinopatili hastalar (PDR grubu). Optik düşük koherens reflektobiyometri yöntemiyle ölçülen merkezi kornea kalınlığı (MKK), kornea eğriliği (K1 ve K2), kornea çapı (KÇ), aköz derinliği (AD), lens kalınlığı (LK) ve aksiyel uzunluk (AU) değerleri gruplar arasında karşılaştırıldı.

Bulgular: Toplam katılımcıların 40'ı non-DR (22 kadın, 18 erkek), 29'u NPDR (19 kadın, 10 erkek) ve kalan 21'i PDR (13 kadın, 8 erkek) grubunu oluşturdu. Gruplar arasında yaş ve cinsiyet yönünden istatistiksel anlamlı farklılık saptanmadı ( $>0.05$ ). Ortalama MKK değeri; non-DR grubunda, NPDR ve PDR gruplarına göre istatistiksel anlamlı düzeyde ince olarak bulundu ( $p=0.001$ ve $p<0.001$, sırasıyla). Diğer taraftan NPDR ve PDR grupları arasında ortalama MKK değeri benzer olarak bulundu ( $\mathrm{p}=0.211)$. Ayrıca, üç grup arasında ortalama K1 ve K2, KÇ, AD, LK ve AU açısından istatistiksel anlamlı fark bulunmadı ( $\mathrm{p}>0.05)$.

Sonuç: PDR ve NPDR'li hastalarda MKK değeri, retinopatisi olmayan Tip 2 DM'li hastalara göre anlamlı düzeyde kalın olarak bulunmuş̧tur. Bu durum Tip 2 DM'li hastalarda, retinopatinin varlığının kornea kalınlığını arttırdığını göstermektedir.

Anahtar Kelimeler: biyometri, diyabetik retinopati, kornea, merkezi kornea kalınlığı.

DOI: 10.5798/dicletip.850472

Correspondence / Yazışma Adresi: İrfan Durukan, Yayla Mah. Şehit Mustafa Ercigez Cad. No:21, Keçiören/Ankara, Türkiye e_mail: dr.irfandurukan@gmail.com 


\title{
Effect of Retinopathy on the Anterior Segment parameters of the Eye in Type 2 Diabetes Mellitus
}

\begin{abstract}
Objective: To compare the axial length and anterior segment structures in patients with Type 2 diabetes mellitus (DM) at different stages of retinopathy.

Method: Patients with Type 2 DM included in this study were divided into three groups according to diabetic retinopathy (DR) status: patients without retinopathy (non-DR group), patients with non-proliferative diabetic retinopathy (NPDR group), and patients with proliferative diabetic retinopathy (PDR group). The values of central corneal thickness (CCT), corneal curvature (K1 and K2), corneal diameter (CD), aqueous depth (AD), lens thickness (LT) and axial length (AL) measured by optical low coherence reflectobiometry method were compared between the groups.
\end{abstract}

Results: Forty of total participants were non-DR (22 females, 18 males), 29 were NPDR (19 females, 10 males) and the remaining 21 were PDR ( 13 females, 8 males) group. There were not any statistically significant differences between the groups in terms of age and gender $(p>0.05)$. The mean CCT value was found to be statistically significantly thinner in the non-DR group compared to NPDR and PDR groups ( $\mathrm{p}=0.001$ and $\mathrm{p}<0.001$, respectively). On the other hand, the mean CCT value was similar in NPDR and PDR groups ( $\mathrm{p}=0.211$ ). In addition, mean K1 and K2, CD, AD, LT and AL parameters were not statistically different between all three groups $(p>0.05)$.

Conclusion: CCT was found to be significantly thicker in patients with PDR and NPDR than in patients with Type 2 DM without retinopathy. This indicates that the presence of retinopathy increases corneal thickness in patients with Type 2 DM.

Keywords: biometry, diabetic retinopathy, cornea, central corneal thickness.

\section{GíRiş}

Hiperglisemi ile karakterize diyabetes mellitus (DM) dünyadaki en yaygın sistemik hastalıklardan biri olup, büyük bir küresel halk sağlığı sorunudur. DM'nin 2011 yılında dünya çapında 366 milyon kişiyi etkilediği; 2030 ve 2040 yılları itibariyle bu sayının sırasıyla 555 ve 640 milyon kişiye ulaşacağı tahmin edilmektedir ${ }^{1}$. Tip $1 \mathrm{DM}$, vücudun insülin üretememesinden kaynaklanır ve kişinin insülin enjekte etmesini veya insülin pompası kullanmasını gerektirir ${ }^{2}$. Tip 2 DM ise hücrelerin insülini uygun şekilde kullanamadıkları insülin direncinden kaynaklanır². DM'li hastalarda uzun süreli hiperglisemi sebebiyle, özellikle gözler, böbrekler, sinirler, kalp ve kan damarlarında hasarlar görülebilmektedir².

Diyabetik retinopati (DR), dünya çapında yaklaşık 4.2 milyon insanı etkileyen, gelişmiş ülkelerde bile körlüğün önde gelen nedenlerinden biridir ${ }^{3}$. DR, küçük damarları etkiler ve etkilenen damarlarda bazal membranın çok katlı hale gelmesine ve endotelyal hücrelerin ve perisitlerin dejenerasyonuna neden olur ve bu durum kapiller tıkanıklık ve sızıntıyla sonuçlanır ${ }^{3,4}$. DR; non-proliferatif diyabetik retinopati (NPDR) ve proliferatif diyabetik retinopati (PDR) olmak üzere iki ana grupta değerlendirilir. NPDR evresinde lezyonlar sadece retina içinde sinırliyken; PDR evresinde retina lezyonlarına ek olarak vitreus içine doğru ilerleme görülmektedir5. Retinal patolojilere ilaveten gözün kornea, iris, siliyer cisim ve lens gibi ön segment yapıları da DM'den etkilenebilmektedir. Diyabetli hastalar artmış katarakt riski, kornea endotel hasarl, tekrarlayan kornea erozyonları șeklinde keratoepitelyopati, kalıcı epitel defektleri, azalmış kornea duyarlılığı ve yüzeysel keratit riski gibi birçok ön segment problemi açısından da risk altındadır6,7.

$\mathrm{Bu}$ çalışmada, optik düşük koherens reflektobiyometri cihazıyla farklı retinopati evrelerindeki Tip 2 DM'li hastalarda ölçülen aksiyel uzunluğun ve ön segment yapılarının 
değerlendirilmesi ve retinopati evresinin bu parametreler üzerine etkisinin araştırılması amaçlanmıştır.

\section{YÖNTEMLER}

Kesitsel gözlem prospektif tipteki bu klinik çalışma Ankara Numune Eğitim ve Araştırma Hastanesinden alınan etik kurul onayı (E-18652) sonrası Helsinki Deklarasyonu'na uygun olarak gerçekleştirildi. Çalışma kapsamındaki tüm hastalardan onam alındı.

Çalışmaya sadece Tip 2 DM tanısı olan olgular dahil edildi ve tüm katılımcıların sadece sağ gözlerine ait veriler analiz edildi. Çalışmaya dahil edilen DM'li hastalarda, DR'nin varlığı ve evreleri renkli fundus fotoğrafi, fundus floresein anjiyografi ve/veya optik koherens tomografi kullanılarak araştırıldı. DR'nin farklı evrelerini tanımlamak için Diyabetik Retinopati Erken Tedavi Çalışması kriterleri kullanıldı ${ }^{8}$. Bu evreleme sistemine göre hastalar; retinopatisi olmayan olgular (non-DR), NPDR'li olgular ve PDR'li olgular olarak üç gruba ayrıldı. Ayrıca tüm diyabetik olguların tanı aldıktan itibaren hastalık süresi (DM süresi) ve son glikolize hemoglobin (HbA1c) değerleri kaydedildi.

Çalışmanın dışlama kriterleri: geçirilmiş oküler cerrahi, 6.00 diyoptriden yüksek sferik, 3 diyoptriden yüksek silindirik kırma kusuru, glokom, üveit, kornea hastalıkları (korneal ektazi ve distrofileri, kornea opasiteleri), şiddetli kuru göz mevcudiyeti, kontakt lens kullanımı, kronik topikal oftalmik ilaç kullanımı ile ön segment parametrelerini etkileyebilen DM dışındaki diğer sistemik hastalıklar olarak belirlendi.

Tüm olgulara ait demografik veriler kaydedildikten sonra Snellen eșeli kullanılarak düzeltilmiş görme keskinliği ölçümü, pnömotonometri ile göz içi basıncı ölçümü, biyomikroskobik muayene ve dilatasyonlu fundus muayenesinden oluşan kapsamlı bir oftalmolojik muayene tüm katılımcılara yapıldı. Dilatasyonlu fundus muayenesinden en az 3 gün sonrasında, optik düşük koherens reflektobiyometri ölçümleri aynı cihaz (LenStar LS 900, Haag Streit Diagnostic) kullanılarak ve aynı hekim tarafından gerçekleştirildi. Optik düşük koherens reflektobiyometri, $820 \mathrm{~nm}$ dalga boylu diod ışık kullanarak merkezi kornea kalınlığı (MKK), kornea eğriliği (yatay ve dikey meridyen, K1 ve K2), kornea çapı (limbustan limbusa kornea çapı, KÇ), aköz derinliği (AD), lens kalınlığı (LK) ve aksiyel uzunluk (AU) parametrelerini yüksek geçerlilik ve güvenirlikle ölçebilen kontakt olmayan bir ölçüm aracıdır9,10. Kornea kalınlığındaki gün içi değişikliklerin etkisini en aza indirmek için ölçümler sabah saat 9 ile 12 arasında yapıldı. Ölçümler sonucunda elde edilen MKK, K1 ve K2, $\mathrm{KC}, \mathrm{AD}, \mathrm{LK}$ ve $\mathrm{AU}$ parametreleri kaydedildi ve üç grup arasında karşılaştırıldı.

\section{İstatistiksel Analiz}

Veri analizinde SPSS 22.0 (SPSS Inc., Chicago, ABD) yazılımı kullanılarak gerçekleştirildi. Verilerin tanımlanması sayı, yüzde, ortalama ve standart sapma değerleri ile gerçekleștirildi. Verilerin normal dağılımını değerlendirmede Kolmogorov-Smirnov dağılım testi kullanıldı. Kategorik değişkenler ki-kare testi kullanılarak analiz edildi. Farklı retinopati evrelerindeki DM'li 3 grubun karşılaştırılmasında normal dağılım gösteren parametreler için Tek yönlü varyans analizi (ANOVA) testi, normal dağılım göstermeyen parametreler için ise KruskalWallis testi kullanıldı. İkili grup karşılaştırmaları için ayrıca post-hoc testler yapıldı. Korelasyon analizi için Pearson korelasyon testi kullanıldı. P değerinin 0.05 'den düşük olması istatistiksel anlamlılık olarak kabul edildi.

\section{BULGULAR}

Çalışma kapsamında toplam 90 DM'li olgunun 90 gözü analiz edildi. Toplam katılımcıların 40'ı non-DR (22 kadın, 18 erkek), 29'u NPDR (19 kadın, 10 erkek) ve kalan 21'i PDR (13 kadın, 8 erkek) grubunu oluşturdu. Ortalama yaş non-DR, NPDR ve PDR olgularında sırasıyla $52.3 \pm 9.1,53.0 \pm 10.1$ ve 
$55.5 \pm 10.5$ yll olarak bulundu. Yaş ve cinsiyet bakımından gruplar arasında istatistiksel anlamlı farklılık izlenmedi ( $\mathrm{p}>0.05$, Tablo 1). Ortalama HbA1c değeri, non-DR grubunda \%7.3 \pm 1.3 ; NPDR grubunda $\% 7.9 \pm 1.8$ ve PDR grubunda $\% 8.8 \pm 2.0$ olarak hesaplandı ( $\mathrm{p}<0.001)$. Grupların demografik özellikleri, ortalama DM süresi ve HbA1c değerleri Tablo 1'de sunulmuştur.

Tablo I: Diyabetik olguların farklı retinopati evrelerinde demografik özelliklerin ve HbA1c düzeylerinin karşılaştırılması.

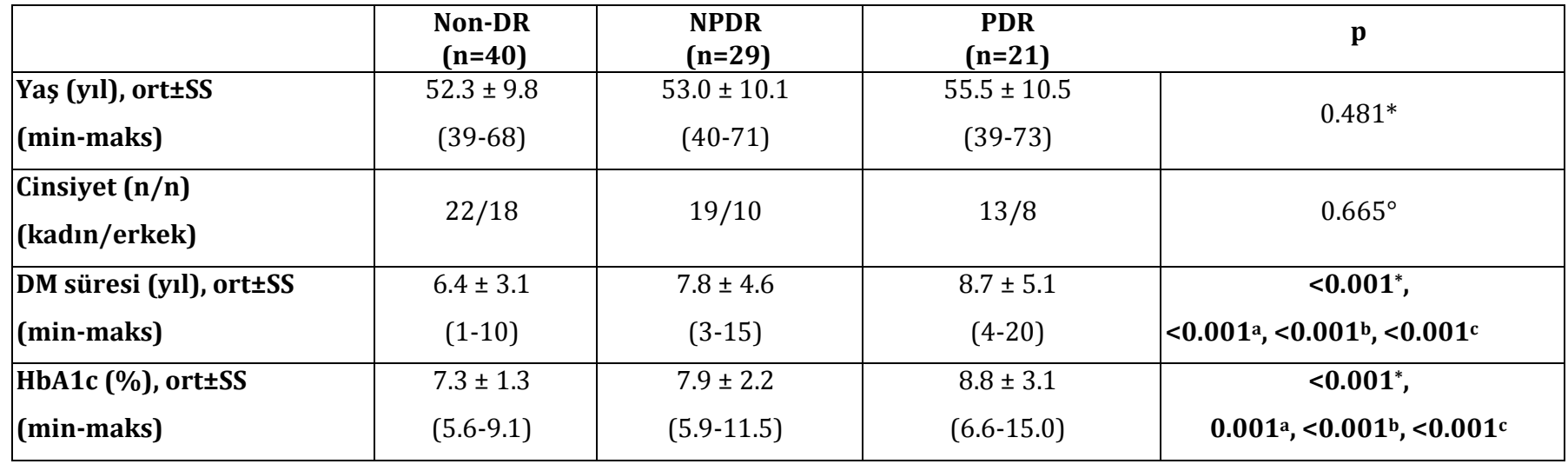

NPDR: Non-proliferatif diyabetik retinopati, PDR: Proliferatif diyabetik retinopati; HbA1c: Glikolize hemoglobin *Tek yönlü varyans analizi (ANOVA)

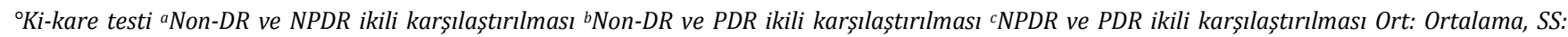
Standart sapma İstatistiksel anlamlı değerler koyu olarak gösterilmiştir.

Diyabetik olguların farklı retinopati evrelerinin optik düşük koherens reflektobiyometri ile elde edilen ön segment parametreleri ve aksiyel uzunluk değerleri Tablo 2'de gösterilmiştir. Ortalama MKK değeri non-DR grubunda $521.35 \pm 28.74 \mu \mathrm{m}$, NPDR grubunda $533.26 \pm 33.88 \mu \mathrm{m}$ ve PDR grubunda $537.71 \pm 35.11 \mu \mathrm{m}$ olarak ölçüldü. Ortalama MKK değeri; non-DR grubunda, NPDR ve PDR grubuna

Tablo II: Ön segment parametrelerinin ve aksiyel uzunluğun diyabetik olguların farklı retinopati evrelerinde karşılaştırılması.

\begin{tabular}{|c|c|c|c|c|}
\hline & $\begin{array}{c}\text { Non-DR } \\
(n=40) \\
\text { Ort } \pm S S \\
\text { (min-maks) }\end{array}$ & $\begin{array}{c}\text { NPDR } \\
(n=29) \\
\text { Ort } \pm S S \\
\text { (min-maks) }\end{array}$ & $\begin{array}{c}\text { PDR } \\
(n=21) \\
\text { Ort } \pm S S \\
\text { (min-maks) }\end{array}$ & $\mathbf{P}$ \\
\hline MKK $(\mu \mathrm{m})$ & $\begin{array}{c}521.35 \pm 28.74 \\
(490-557)\end{array}$ & $\begin{array}{c}533.26 \pm 33.88 \\
(481-565)\end{array}$ & $\begin{array}{c}537.71 \pm 35.11 \\
(477-569)\end{array}$ & $\begin{array}{c}\mathbf{0 . 0 0 1}{ }^{*} \\
\mathbf{0 . 0 0 1}^{\mathrm{a}},<\mathbf{0 . 0 0 1}^{\mathrm{b}}, 0.211^{\mathrm{c}}\end{array}$ \\
\hline K1 (D) & $\begin{array}{c}43.23 \pm 1.71 \\
(39.16-45.66)\end{array}$ & $\begin{array}{c}43.42 \pm 1.60 \\
(40.10-45.55)\end{array}$ & $\begin{array}{c}43.33 \pm 1.76 \\
(39.10-46.15) \\
\end{array}$ & $0.885^{*}$ \\
\hline K2 (D) & $\begin{array}{c}44.24 \pm 1.66 \\
(40.75-48.02) \\
\end{array}$ & $\begin{array}{c}44.71 \pm 1.60 \\
(40.90-47.75) \\
\end{array}$ & $\begin{array}{c}44.10 \pm 1.70 \\
(40.75-48.25)\end{array}$ & $0.780^{*}$ \\
\hline KÇ (mm) & $\begin{array}{c}12.11 \pm 0.38 \\
(11.40 \pm 12.39)\end{array}$ & $\begin{array}{c}12.09 \pm 0.47 \\
(11.34-12.83)\end{array}$ & $\begin{array}{c}12.11 \pm 0.40 \\
(11.41-12.59)\end{array}$ & $0.901^{*}$ \\
\hline AD (mm) & $\begin{array}{c}3.09 \pm 0.31 \\
(2.26-4.30) \\
\end{array}$ & $\begin{array}{c}3.11 \pm 0.29 \\
(2.31-4.29) \\
\end{array}$ & $\begin{array}{c}3.07 \pm 0.26 \\
(2.35-4.21) \\
\end{array}$ & $0.301 \pi$ \\
\hline LK (mm) & $\begin{array}{l}4.06 \pm 0.41 \\
(3.71-4.52) \\
\end{array}$ & $\begin{array}{l}4.10 \pm 0.52 \\
(3.60-4.63) \\
\end{array}$ & $\begin{array}{l}4.04 \pm 0.52 \\
(3.63-4.65) \\
\end{array}$ & $0.601^{*}$ \\
\hline$A U(\mathrm{~mm})$ & $\begin{array}{c}22.65 \pm 0.85 \\
(21.30-23.96) \\
\end{array}$ & $\begin{array}{c}22.85 \pm 1.10 \\
(21.13-24.10)\end{array}$ & $\begin{array}{c}22.57 \pm 1.35 \\
(21.00-24.97) \\
\end{array}$ & $0.356^{*}$ \\
\hline
\end{tabular}

MKK: Merkezi kornea kalınlığı; K1 ve K2: Keratometri, KÇ: Kornea çapl; AD: Aköz derinliği; LK: Lens kalınlığı; AU; Aksiyel uzunluk; D:Diyoptri

${ }^{*}$ Tek yönlü varyans analizi (ANOVA) ${ }^{a}$ Non-DR ve NPDR ikili karşılaştırılması ${ }^{b}$ Non-DR ve PDR ikili karşılaștırılması ${ }^{c} N P D R$ ve PDR ikili karşılaştırılması ${ }^{d}$ Kruskal-Wallis testi Ort: Ortalama; SS, Standart sapma İstatistiksel anlamlı değerler koyu olarak gösterilmiștir. 
Ek olarak, yapılan korelasyon analizinde ortalama DM süresi ve HbA1c düzeyi araştırılan hiçbir ön segment parametresi ile istatistiksel anlamlı ilişki göstermedi ( $\mathrm{p}>0.05)$.

\section{TARTIŞMA}

$\mathrm{Bu}$ çalışmada, optik düşük koherens reflektobiyometri kullanılarak farklı retinopati evrelerindeki Tip 2 DM'li hastaların aksiyel uzunlukları ve ön segment parametreleri değerlendirilerek diyabetik retinopatinin bu parametreler üzerine etkisi araștırılmış ve retinopatisi olan Tip 2 DM'li olgularda, MKK değerinin retinopatisi olmayan diyabetik olgulara kıyasla anlamlı düzeyde kalın olduğu saptanmıştır.

Diyabetik retinopati, diyabetin en çok bilinen ve araștırılan komplikasyonu olsa da, DM gözün tüm yapılarını etkileyebilen bir sistemik hastalıktır. Kornea, DM'li olgularda etkilenebilen önemli ön segment yapılarından biridir ve uzun süreli anormal glikoz metabolizması korneanın epitel, stroma ve endotelinde değişikliklere neden olabilmektedir ${ }^{11}$. Tekrarlayan epitelyal erozyon, gecikmiş korneal yara iyileşmesi ve nörotrofik ülser gibi diyabetik keratopati bulguları DM'li hastaların önemli bir kısmında görülebilmektedir ${ }^{6,7}$. Bunlara ilaveten, kornea endotel hasarl, stromal ve subbasal sinir anomalileri, azalmış endotel hücre dansitesi, kalıcı epitel defektleri, azalmış kornea duyarlılığı, punktat epitelyal keratopati ve superfisyal keratit diyabetli hastalarda görülebilen diğer kornea değişikleri içinde sayllabilmektedir6,7,12.

Merkezi kornea kalınlığı, kornea sağlığının hassas bir göstergesidir ve kornea hidrasyonu ve metabolizması için bir indeks görevi görür. MKK, katarakt ve refraktif ameliyatlarla ilgili kararlar almak ve düzeltilmiş göz içi basıncı hesaplamak için dikkate alınması gereken önemli bir parametredir ${ }^{13}$. Glokomlu hastalarda, MKK'nin dikkate alınmaması veya hatalı değerlendirilmesi, glokom için en önemli ve tedavi edilebilir risk faktörü olan göz içi basıncının fazla veya az ölçülebilmesine neden olabilmektedir ${ }^{13}$. DM'li olgularda hipergliseminin korneal endotelyal aktif sivı pompasının aktivitesindeki azalmaya ve ileri glikasyon son ürünlerinin korneada birikmesine neden olarak kornea morfolojisi ve fonksiyonunda değişikliklere neden olabileceği görüşleri mevcuttur. Hipergliseminin endotel disfonksiyonuna ve bunun sonucunda da stromal hidrasyona ve korneanın şişmesine sebep olarak DM'li olgularda daha yüksek MKK ölçümlerine neden olduğu düşünülmektedir. McNamara ve ark. ${ }^{14}$ diyabetik olgularda hiperglisemik etkinin korneanın hidrasyonunu bozarak yapısını değiştirdiğini ve bu sebeple DM'li olgularda korneal kalınlığın etkilendiğini bildirmişlerdir. Weston ve ark. ${ }^{15}$ diyabetik kornealarda endotelyal geçirgenliğin hipoksinin farklı evrelerinde azaldığını bildirirken; Keoleian ve ark. ${ }^{16}$ hipoksik koşullarda kornea kalınlığında farklılık saptamamışlardır. Bir diğer görüş ise DM'li olgularda pleomorfizm ve polimegatizmin, yani kornea endotel hücre şeklinin ve diziliminin değişmesinin, bu olgularda kornea kalınlığının artmaya eğilim göstermesinin nedeni olabileceğidir $^{17}$. Mete ve ark. ${ }^{18}$ Tip 2 DM'de MKK'nin sağlıklı olgulara kıyasla istatistiksel anlamlı düzeyde kalın olduğunu göstermişlerdir. Papadokou ve ark. ${ }^{19}$ ile ElAgamy ve Alsubaie ${ }^{20}$ tarafından yapılan çalışmalarda da Tip 2 DM'li hastalarda kontrol grubuna kıyasla MKK değerinin artmış olduğu ancak bu artışın istatistiksel anlamlı düzeye ulaşamadığı rapor edilmiştir. Geniş katılımcı sayıları ile yapılan popülasyon çalışmalarında da DM'li hastalarda sağlıklı olgulara kıyasla MKK değerinin istatistiksel anlamlı derecede artmış olduğu ve hipergliseminin artmış kornea kalınlığı ile ilişkili olduğu bildirilmiştir ${ }^{21,22}$. Ancak DM'li olgularda, retinopati durumunun MKK değerleri üzerine etkisinin değerlendirildiği çalışmalar birbirinden farklı 
sonuçlar rapor etmektedir. Ozdamar ve ark. ${ }^{23}$ ultrasonik pakimetri ile ölçüm yaptıkları çalışmalarında, Tip 2 DM'li olgularda MKK değerinin kontrol grubuna göre istatistiksel düzeyde anlamlı artış gösterdiğini ancak DM'li hastaların retinopati durumuna göre karşılaştırılmasında non-DR, NPDR ve PDR'li gruplar arasında anlamlı fark olmadığını göstermişlerdir. Benzer șekilde, Zengin ve ark ${ }^{24}$. Orbscan II ile MKK ölçümü yaptıkları çalışmalarında, MKK'nin Tip 2 DM'li olgularda sağlıklı olgulara kıyasla anlamlı artış gösterdiğini ancak retinopatinin MKK üzerine anlamlı etkisi olmadığını bildirmişlerdir. Çekiç ve $\operatorname{ark}^{25}$. ise sağlıklı olgular, retinopatisi olmayan Tip 2 DM'li hastalar, başlangıç retinopatili hastalar ve proliferatif retinopatili hastaların MKK değerlerini ultrasonik pakimetri ile ölçerek karşılaştırmışlar ve PDR'li olgularda MKK değerinin diğer üç gruba kıyasla istatistiksel anlamlı derecede arttığını ancak sağlıklı olgular, retinopatisi olmayan Tip 2 DM'li hastalar ve başlangıç retinopatili hastalar arasında istatistiksel anlamlı farklılık olmadığını saptamışlardır. Sasmal ve $\operatorname{ark}^{26}$. ise ultrasonik pakimetri ve speküler mikroskobi ile yaptıkları çalışmalarında PDR ve NPDR'li olgularda retinopatisi olmayan DM'li olgulara göre MKK'nin anlamlı düzeyde kalın olduğunu ve NPDR ile PDR grupları arasında anlamlı farklılık olmadığını rapor etmişlerdir. Benzer şekilde, Torun ve $\operatorname{ark}^{27}$. DM'li hastalarda merkezi korneal kalınlık ölçümlerinin sağlıklı kontrol grubuna göre istatistiksel anlaml düzeyde kalın olduğunu ve retinopati varlığında, bu anlamlılığın arttığını göstermişlerdir. Bizim çalışmamızda da benzer şekilde NPDR ve PDR grubunda, non-DR grubuna göre MKK ölçümlerinin istatistiksel anlamlı düzeyde yüksek olduğu; yani retinopati mevcudiyetinin diyabetik hastalarda MKK'de kalınlaşma ile ilişkili olduğu saptanmıştır. Ayrıca çalışmamızda yapılan korelasyon analizinde ortalama DM süresi ve HbA1c düzeyi, araştırılan hiçbir ön segment parametresi ile istatistiksel anlamlı ilişki göstermemiştir. Benzer şekilde, Suraida ve $\operatorname{ark}^{28}$. retinopatisi olmayan DM'li hastalarda ve NPDR'li hastalarda ön segment optik koherens tomografisi ile elde edilen ön segment parametrelerini $\mathrm{HbA1c}$ düzeyi ile korele etmişler ve DM'li hastalarda retinopati durumuna bakılmaksızın HbA1c düzeyi ile hiçbir ön segment parametresi arasında anlamlı bir ilişki olmadığını bildirmişlerdir. Yine Tip 2 DM'li hastalarda yapılan başka bir çalışmada da DM süresi, HbA1c düzeyi ve retinopati şiddetinin MKK ile anlamlı bir korelasyon göstermediği rapor edilmiştir ${ }^{29}$.

Çalışmamız için bazı kısıtlayıcı durumlar söz konusudur. İlk olarak örneklem büyüklüğü rölatif olarak küçüktür. Ayrıca çalışmada retinopatinin ön segment parametrelerine etkisi değerlendirilmek istendiği için, sadece Tip 2 DM'li hastalar çalışmaya dahil edilmiş ve bu nedenle DM'si olmayan sağlıklı olgularla diyabetikler arasındaki ön segment farklılıkları değerlendirilememiștir.

\section{SONUÇ}

Proliferatif ve non-proliferatif diyabetik retinopatili hastalarda MKK değeri retinopatisi olmayan Tip 2 DM'li hastalara göre anlamlı düzeyde kalın olarak bulunmuştur. Bu durum, Tip 2 DM'li hastalarda, retinopatinin varlığının kornea kalınlığını arttırdığını göstermektedir. Ancak bu sonuçların doğrulanması için daha geniş hasta grubuyla daha fazla çalışmaya ihtiyaç vardır.

Etik Kurul Onayı: Kesitsel gözlem prospektif tipteki bu klinik çalışma Ankara Numune Eğitim ve Araştırma Hastanesinden alınan etik kurul onayı (E-18-652) sonrası Helsinki Deklarasyonu'na uygun olarak gerçekleştirildi.

Çıkar Çatışması Beyanı: Yazarlar çıkar çatışması olmadığını bildirmişlerdir.

Finansal Destek: Bu çalıșma herhangi bir fon tarafından desteklenmemiştir. 
Declaration of Conflicting Interests: The authors declare that they have no conflict of interest.

Financial Disclosure: No financial support was received.

\section{KAYNAKLAR}

1. International Diabetes Federation. IDF Diabetes Atlas. 2015;7th Edition: http://www.diabetesatlas.org/

2. Eser BE, Yazgan ÜC, Gürses SA, Aydın M. Diabetes Mellitus ve Epigenetik Mekanizmalar. Dicle Tıp Dergisi. 2016; 43: 375-82.

3. Vieira-Potter VJ, Karamichos D, Lee DJ. Ocular complications of diabetes and therapeutic approaches. Biomed Res Int. 2016; 2016: 3801570.

4. Kadayıfçılar S. Güncel Bilgiler Işı̆̆ında Diyabetik Retinopati Patogenezi. Türkiye Klinikleri J Ophthalmol-Special Topics. 2014; 7: 6-11.

5. İnan S. Diyabetik Retinopati ve Etiyopatogenezi. Kocatepe Tıp Dergisi. 2014; 15: 207-17.

6. Han SB, Yang HK, Hyon JY. Influence of diabetes mellitus on anterior segment of the eye. Clin Interv Aging. 2018; 14: 53-63.

7. Herse PR. A review of manifestations of diabetes mellitus in the anterior eye and cornea. Am J Optom Physiol Opt. 1988; 65: 224-30.

8. Early Treatment Diabetic Retinopathy Study Design and Baseline Characteristics. ETDRS report number 7. Ophthalmology. 1991; 98: 741-56.

9. Bayhan HA, Bayhan SA, Muhafız E, Can İ. Optik Düşük Koherens Reflektometri ve Kombine Scheimpflug-Placido Disk Topografisi ile Değerlendirilen Ön Segment Parametrelerinin Karşılaştırılması. Glo-Kat. 2013; 8: 78-82.

10. Huerva V, Ascaso FJ, Soldevila J, Lavilla L. Comparison of anterior segment measurements with optical low-coherence reflectometry and rotating dual Scheimpflug analysis. J Cataract Refract Surg. 2014; 40: 1170-6.

11. Goldich Y, Barkana Y, Gerber Y, et al. Effect of diabetes mellitus on biomechanical parameters of the cornea. J Cataract Refract Surg. 2009; 35: 715-9.
12. Ljubimov AV. Diabetic complications in the cornea. Vision Res. 2017; 139: 138-52.

13. Patwardhan AA, Khan M, Mollan SP, Haigh P. The importance of central corneal thickness measurements and decision making in general ophthalmology clinics: a mesked observational study. BMC Ophthalmol. 2008; 8: 1.

14. McNamara NA, Brand RJ, Polse KA, Bourne WM. Corneal function during normal and high serum glucose levels in diabetes. Invest Ophthalmol Vis Sci. 1998; 39: 3-17.

15. Weston BC, Bourne WM, Polse KA, Hodge DO. Corneal hydration control in diabetes mellitus. Invest Ophthalmol Vis Sci. 1995; 36: 586-95.

16. Keoleian GM, Pach JM, David OH, Trocme SD, Bourne WM. Structural and functional studies of the corneal endothelium in diabetes mellitus. Am J Ophthalmol. 1992; 113: 64-70.

17. Busted N, Olsen T, Schmitz O. Clinical observations on the corneal thickness and the corneal endothelium in diabetes mellitus. $\mathrm{Br} \mathrm{J}$ Ophthalmol. 1981; 65: 687-90.

18. Mete A, Kimyon S, Çeri S, Koyuncu Ö. Kontrolsüz Tip II Diabetes Mellituslu Hastalarda Santral Kornea Kalınlığı ve Kornea Endoteli Değiş̧iklikleri. Türkiye Klinikleri J Ophthalmol. 2018; 27: 135-9.

19. Papadakou P, Chatziralli I, Papathanassiou M, et al. The effect of diabetes mellitus on corneal endothelial cells and central corneal thickness: A case control study. Ophthalmic Res. 2020 Mar 13. doi: 10.1159/000507197. Online ahead of print.

20. El-Agamy A, Alsubaie S. Corneal endothelium and central corneal thickness changes in type 2 diabetes mellitus. Clin Ophthalmol. 2017; 11: 481-6.

21. Luo XY, Dai W, Chee ML, et al. Association of diabetes with central corneal thickness among a multtiethnic asian population. JAMA Netw Open. 2019; 2: 186647.

22. Su DH, Wong TY, Wong WL, et al; Singapore Malay Eye Study Group. Diabetes, hyperglycemia, and central corneal thickness: the Singapore Malay Eye Study. Ophthalmology. 2008; 115: 964-8.

23. Ozdamar Y, Cankaya B, Ozalp S, Acaroglu G, Karakaya J, Ozkan SS. Is there a correlation between 
diabetes mellitus and central corneal thickness? J Glaucoma. 2010; 19: 613-6.

24. Zengin MÖ, Özbek Z, Arıkan G, Durak İ, Saatçi AO. Does central corneal thickness correlate with haemoglobin A1c level and disease severity in diabetes type II? Turk J Med Sci. 2010; 40: 675-80.

25. Çekiç O, Totan Y, Hepşen IF, Bayramlar H, Aydın E. Tip 2 Diyabetli Hastalarda Kornea Endotel Fonksiyonunun Ultrasonik Pakimetreyle Incelenmesi. T. Oft. Gaz. 2000; 30: 686-91.

26. Sasmal NK, Das S, Singh S. Association of central corneal thickness and central endothelial cell count with progressive stages of diabetic retinopathy. J Evid Based Med Health. 2017; 4: 4924-8.

27. Torun B, Ülkü G, Yllmaz T. Diyabetes Mellituslu Hastalarda Santral Kornea Kalınlığının Değerlendirilmesi. Fırat Tıp Dergisi. 2010; 15: 12830.

28. Suraida AR, Ibrahim M, Zunaina E. Correlation of the anterior ocular segment biometry with $\mathrm{HbA1c}$ level in type 2 diabetes mellitus patients. PLoS One. 2018; 13: 0191134.

29. Islam QU. Effect of diabetes mellitus on central corneal thickness - A comparative study. Pak J Ophthalmol. 2017; 33: 126-31. 